\title{
recillunds
}

Revista Cientifica Mundo de la Investigación y el Conocimiento

Miguel Ángel Núñez Núñez ${ }^{a}$; Alfonso Gonzalo Torres Alvarado ${ }^{b}$

Políticas económicas que fomenten la transformación de basura orgánica e inorgánica en material de uso, como medidas del impacto ambiental

Economic policies that promote the transformation of organic and inorganic garbage into use material, as measures of environmental impact

Revista Científica Mundo de la Investigación y el Conocimiento. Vol. 3 núm.3. Esp., noviembre, ISSN: 2588-073X, 2019, pp. 333-367

DOI: $10.26820 /$ recimundo/3.(3.Esp).noviembre.2019.333-367

URL: http://recimundo.com/index.php/es/article/view/606

Código UNESCO: 53 Ciencias Económicas

Tipo de Investigación: Artículo de Revisión

(C) RECIMUNDO; Editorial Saberes del Conocimiento, 2019

Recibido: 15/09/2019

Aceptado: 23/10/2019

Publicado: 30/11/2019

Correspondencia: deangeln@yahoo.es

a. Diploma Superior en Finanzas Corporativas; Magister en Finanzas y Proyectos Corporativos; Máster en Dirección Estratégica en Tecnología de la Información; Economista; Ingeniero en Electricidad Especialización Electrónica; Investigador Independiente; Guayaquil, Ecuador; deangeln@yahoo.es

b. Diploma Superior en Pedagogía Universitaria; Magister en Negocios Internacionales y Gestión de Comercio Exterior; Economista; Investigador Independiente; Guayaquil, Ecuador; torresa777@ hotmail.com 


\section{Políticas económicas que fomenten la transformación de basura orgánica e inorgánica en material de uso, como medidas de impacto ambiental}

Vol. 3, núm. 3 Esp., (2019)

Miguel Ángel Núñez Núñez; Alfonso Gonzalo Torres Alvarado

\section{RESUMEN}

El desarrollo de nuevos conocimientos ha permitido generar una serie de tecnologías con la finalidad de garantizar satisfacer las necesidades básicas. Esto ha permitido el creciente efecto negativo de los desperdicios, desechos o basura impulsando la alta contaminación delos suelos, aire y agua en las diferentes latitudes del mundo. En Ecuador, el creciente desarrollo económico ha permitido poder aumentar la producción de muchos productos que no sola satisfacen las necesidades, sino que buscan otorgar una mejor calidad de vida a la sociedad, esto ocasiona un impulso a la generación de basura. El objetivo general de esta investigación es analizar las políticas económicas que fomenten la transformación de basura orgánica e inorgánica en material de uso, como medidas del impacto ambiental. La metodología se basó en investigaciones de carácter documental y bibliográfico. Los resultados se basaron en el análisis de la transformación de la basura orgánica e inorgánica y las políticas, mecanismos y aspectos económicos que favorecen la transformación de la basura. Como conclusión existen políticas en pro de defender el derecho a un ambiente sano y a valorar los ecosistemas tal cual lo plantea su carta magna, pero todavía estas no tienen la fuerza para poder establecer nuevas formas de presión que sean tanto administrativas como penales, pero a su vez deben cambiar la cultura de los ciudadanos en la reutilización de la basura como materia prima en la fabricación de otros materiales de uso, permitiendo generar una nueva forma de financiamiento que debe producir nuevas políticas económicas en el país.

Palabras Clave: Tecnología; Basura; Contaminación; Reciclaje; Política económica 


\title{
Políticas económicas que fomenten la transformación de basura orgánica e inorgánica en material de uso, como medidas de impacto ambiental
}

Vol. 3, núm. 3 Esp., (2019)

Miguel Ángel Núñez Núñez; Alfonso Gonzalo Torres Alvarado

\begin{abstract}
The development of new knowledge has allowed to generate a series of technologies with the purpose of guaranteeing to satisfy the basic needs. This has allowed the growing negative effect of waste, debris or garbage driving high pollution of soil, air and water in different latitudes of the world. In Ecuador, the growing economic development has allowed to increase the production of many products that not only meet the needs, but seek to provide a better quality of life to society, this causes a boost to the generation of garbage. The general objective of this research is to analyze the economic policies that promote the transformation of organic and inorganic waste into use material, as measures of environmental impact. The methodology was based on documentary and bibliographic research. The results were based on the analysis of the transformation of organic and inorganic waste and the policies, mechanisms and economic aspects that favor the transformation of waste. In conclusion, there are policies in favor of defending the right to a healthy environment and valuing ecosystems as stated in its magna Carta, but they still do not have the strength to establish new forms of pressure that are both administrative and criminal, but in their They must also change the culture of citizens in the reuse of garbage as a raw material in the manufacture of other materials of use, allowing to generate a new form of financing that must produce new economic policies in the country.
\end{abstract}

Keywords: Technology; Garbage; Pollution; Recycling; Economic policy 


\section{Políticas económicas que fomenten la transformación de basura orgánica e inorgánica en material de uso, como medidas de impacto ambiental}

Vol. 3, núm. 3 Esp., (2019)

Miguel Ángel Núñez Núñez; Alfonso Gonzalo Torres Alvarado

\section{Introducción.}

Una de los aspectos que se desarrollan en la evolución de la humanidad es la garantía de satisfacer las necesidades del hombre. El desarrollo de soluciones ha permitido que se generan más conocimiento y a su vez más investigaciones que permitan demostrar métodos más sofisticadas y revolucionarias. Estas técnicas producen impactos en la vida de los ciudadanos ejerciendo una mejor calidad de vida. También producen impactos en el medio ambiente donde se generan y desarrollan las nuevas soluciones.

El desarrollo del conocimiento, indudablemente genera un impacto producto del desarrollo de tecnologías que permiten un desagravio a los ecosistemas. El impacto ambiental es la alteración significativa de los sistemas naturales y transformados, y de sus recursos, provocada por acciones humanas, es decir se expresan en las diversas actividades en ambientes naturales como en aquellos que resultan de la intervención y creación humana (Espinoza, 2001). En la Figura 1 se puede observar la dimensión ambiental y los sistemas ambientales. 


\section{Políticas económicas que fomenten la transformación de basura orgánica e inorgánica en material de uso, como medidas de impacto ambiental}

Vol. 3, núm. 3 Esp., (2019)

Miguel Ángel Núñez Núñez; Alfonso Gonzalo Torres Alvarado

Figura 1. (A) Integración de los sistemas físicos, biológicos y humanos en la dimensión ambiental y (B) condición actual de los sistemas ambientales
(A)

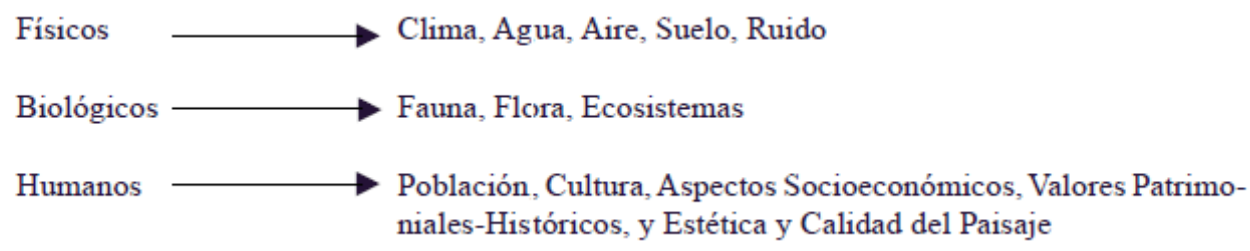
(B)

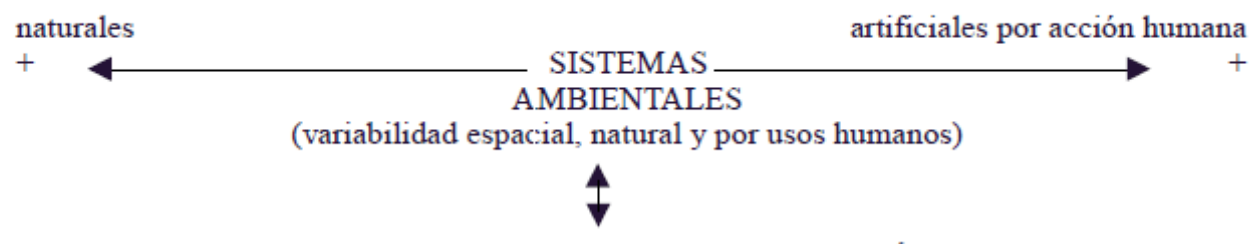
ACTIVIDADES DE TRANSFORMACIÓN
- Caza y Recolección
- Urbanización
- Pesquería
- Minería
- Transporte
- Energía
- Agricultura
- Ganadería
- Silvicultura
- Industria
- Otros

Fuente: (Espinoza, 2001)

En la Figura 2 se puede visualizar el concepto del impacto ambiental. Según Wathern(1988), el impacto ambiental se define como "El cambio en un parámetro ambiental, en un determinado período y en una determinada área, que resulta de una actividad dada, comparado con la situación que ocurriría si esa actividad no hubiera sido iniciada”. (pág. 37). 


\section{Políticas económicas que fomenten la transformación de basura orgánica e inorgánica en material de uso, como medidas de impacto ambiental}

Vol. 3, núm. 3 Esp., (2019)

Miguel Ángel Núñez Núñez; Alfonso Gonzalo Torres Alvarado

Figura 2. Concepto de impacto ambiental.

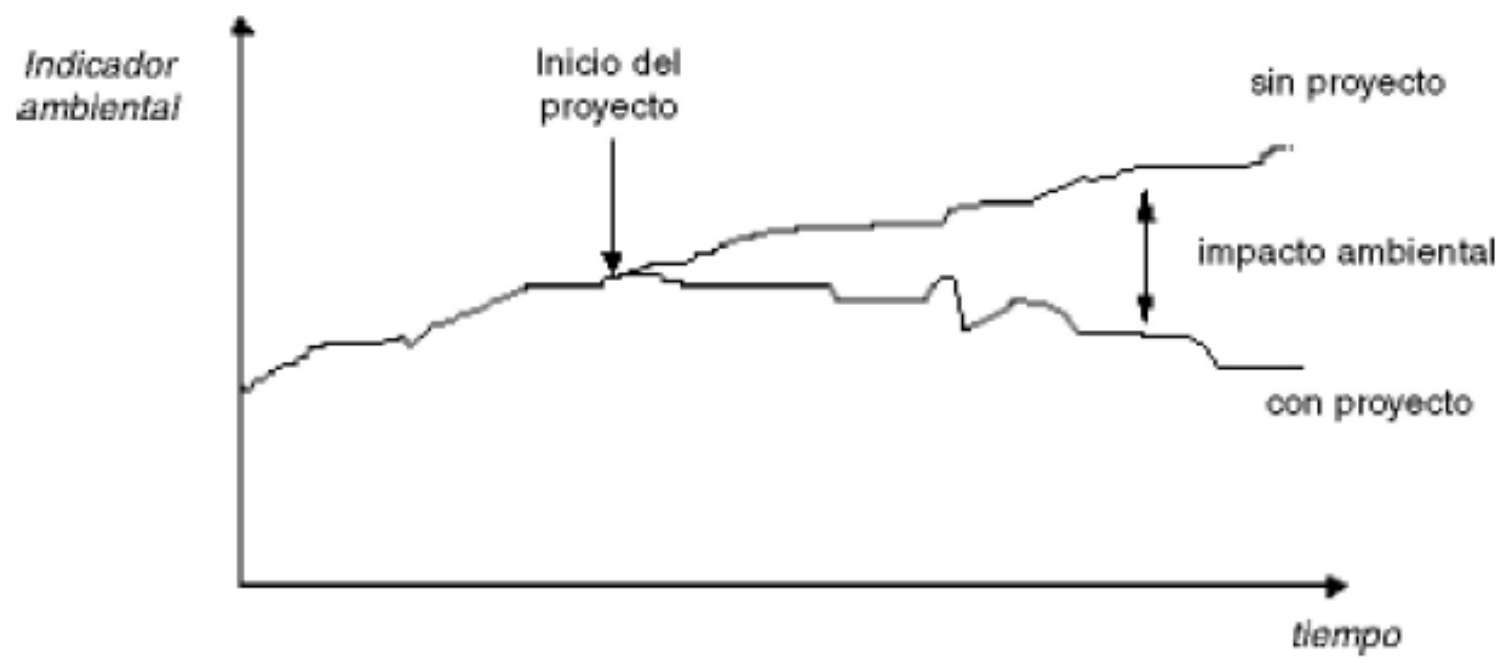

Fuente: (Wathern, 1988)

Por supuesto, estos impactos ambientales tienen como una de las consecuencias a la contaminación. La contaminación ambiental se produce de manera exponencial producto de la obsolescencia programada que tiene la sociedad en la búsqueda de insaciabilidad de consumo de productos sin necesidad. Por lo cual, la contaminación es causada por la presencia o liberación de formas de materia o energía, donde se la puede representar en unidades físicas mensurables; en consecuencia, se pueden establecer límites o patrones(Sánchez, 2011).

Estas unidades físicas y medibles representan en si la valoración del impacto ambiental que genera el desarrollo de esa nueva tecnología o producto. Estos impactos generan una debilidad en el desarrollo sostenible de los ecosistemas. El consumo en masa de producto sin evaluación de estándares de calidad y de protección al medio ambiente compromete al ambiente en el futuro no muy lejano. 


\section{Políticas económicas que fomenten la transformación de basura orgánica e inorgánica en material de uso, como medidas de impacto ambiental}

Vol. 3, núm. 3 Esp., (2019)

Miguel Ángel Núñez Núñez; Alfonso Gonzalo Torres Alvarado

"El desarrollo sostenible se vincula a la satisfacción de las necesidades del presente, sin comprometer la habilidad de las futuras generaciones para alcanzar sus propios requisitos. Visiones más recientes lo vinculan con un proceso de mejoramiento sostenido y equitativo de la calidad de vida de las personas, fundado en medidas apropiadas de conservación y protección ambiental”. (Espinoza, 2001, pág. 15).

Es por ello, que nace la evaluación o estudio del impacto ambiental la cual determinará que una acción no modifique o altere el ecosistema en la cual se va a realizar un proyecto o trabajo específico. Es un documento técnico de carácter interdisciplinar que está destinado a predecir, identificar, valorar y considerar medidas preventivas o corregir las consecuencias de los efectos ambientales que determinadas acciones antrópicas pueden causar sobre la calidad de vida del hombre y su entorno (Coria, 2008).

Aunado a estas características existe los mecanismos multidisciplinarios que permiten una evaluación del impacto ambiental más ajustada a la realidad y enfocando en diversas aristas. Es decir, este equipo incorpora en el análisis los aspectos técnico, científico, administrativo, institucional, jurídico y normativo, cumpliendo con todos los procedimientos, las normativas y con base en la información primaria suficiente y eficiente al respecto (Perevochtchikova, 2013).

Este grupo determinara que tanto impacto ha sufrido o sufrirá un sector o ecosistema cuando se realicen labores que involucren un daño perjudicial al medio ambiente. La evaluación del impacto ambiental genera actividades (ver Figura 3) tales como:

“(i) previsión de los impactos potenciales que un determinado proyecto de ingeniería podría causar, en caso de ser implantado; 


\section{Políticas económicas que fomenten la transformación de basura orgánica e inorgánica en material de uso, como medidas de impacto ambiental}

Vol. 3, núm. 3 Esp., (2019)

Miguel Ángel Núñez Núñez; Alfonso Gonzalo Torres Alvarado

(ii) estudio de las alteraciones ambientales ocurridas en una determinada región o determinado lugar, como consecuencia de una actividad individual, o de una serie de actividades humanas, pasadas o presentes; en esta acepción, la evaluación de impacto ambiental, es también llamada evaluación del daño ambiental, o evaluación del pasivo ambiental, ya que se preocupa de los impactos ambientales negativos;

(iii) identificación e interpretación de los "aspectos e impactos ambientales", resultantes de las actividades de una organización, en los términos de las normas técnicas de la serie ISO 14 000;

(iv) análisis de los impactos ambientales, resultantes del proceso de producción, de la utilización y desperdicio de un determinado producto; esta forma particular de evaluación de impacto ambiental, también se conoce como análisis del ciclo de vida”.(Sánchez, 2011, págs. 36-37). 


\section{Políticas económicas que fomenten la transformación de basura orgánica e inorgánica en material de uso, como medidas de impacto ambiental}

Vol. 3, núm. 3 Esp., (2019)

Miguel Ángel Núñez Núñez; Alfonso Gonzalo Torres Alvarado

Figura 3. Principales actividades en la elaboración de un estudio de impacto ambiental.

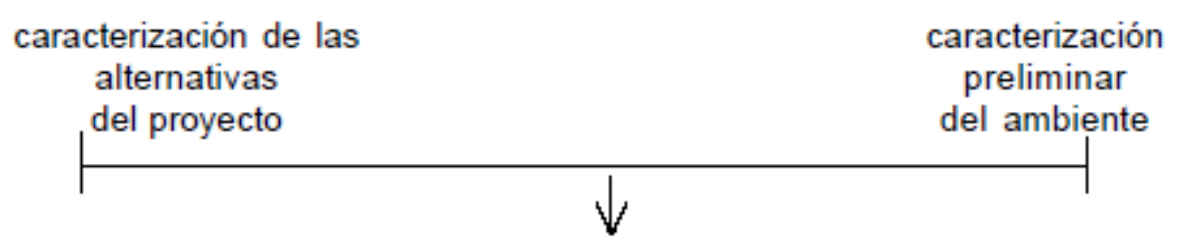

identificación preliminar de los impactos

$\sqrt{ }$

identificación de las cuestiones relevantes

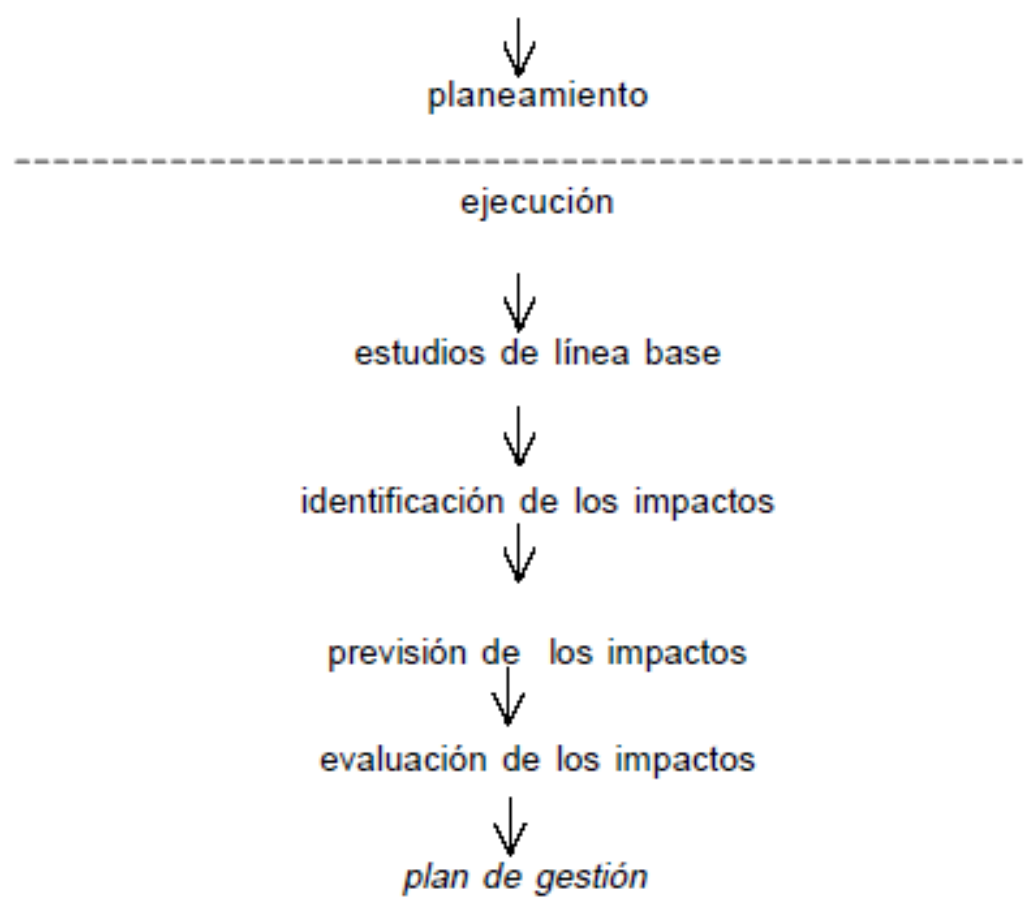

Fuente: (Sánchez, 2011)

Ahora, la contaminación generada por el consumo de la sociedad ha generado un impacto ambiental severo. Parte de esta contaminación son los residuos generados por el consumo masivo de productos por parte de los individuos. Los desechos son necesarios poder determinarlos. Es cualquier material generado en los procesos de extracción, beneficio, transformación, 


\section{Políticas económicas que fomenten la transformación de basura orgánica e inorgánica en material de uso, como medidas de impacto ambiental}

Vol. 3, núm. 3 Esp., (2019)

Miguel Ángel Núñez Núñez; Alfonso Gonzalo Torres Alvarado

producción, consumo, utilización, control o tratamiento, cuya calidad no permite usarlo nuevamente en el proceso que lo generó; al que se le debe aplicar un método de eliminación o deposición final (García Batista, Machado López, \& Minuche, 2017).

Indudablemente, la basura orgánica e inorgánica juega un papel protagónico como desecho que genera contaminación y a su vez produce un alto impacto ambiental para el ecosistema y para la sociedad. Eso por supuesto deja vulnerable los recursos naturales del medio ambiente. Ecuador no escapa a ello. Son escasos y limitados los estudios e investigaciones que se han llevado a cabo con la finalidad de conocer el grado de importancia de los recursos naturales para las personas que habitan en estas áreas y hacen uso de los mismos (Orellana Salas, Portilla, \& Del Cisne, 2018).

"En Ecuador, aunque esa integración constituye una política del Estado sustentada en un marco legal e institucional, los proyectos aun adolecen de estudios de impacto ambiental que evalúen todas las posibles consecuencias de su implementación. Ese problema se evidencia con particular fuerza en la gestión de los residuos urbanos, cuyas deficiencias de manejo generan consecuencias en la salud de la población y en el entorno ecológico". (Macías Fuentes, 2011, pág. 72).

Estos residuos orgánicos e inorgánicos producen alteración de varios factores importantes en el medio ambiente que se traducen en impactos permanentes. Estos parámetros ambientales son el uso del recurso agua, calidad del agua, calidad del aire, aspectos paisajísticos, así como también existe probabilidad de riesgos sobre la seguridad y salud humana (Torres, 2010). 


\section{Políticas económicas que fomenten la transformación de basura orgánica e inorgánica en material de uso, como medidas de impacto ambiental}

Vol. 3, núm. 3 Esp., (2019)

Miguel Ángel Núñez Núñez; Alfonso Gonzalo Torres Alvarado

Existe a nivel internacional leyes y normativas que tienen como factor común la basura cero.

"Los objetivos de la Ley Basura Cero son: reducir progresivamente los materiales no retornables, rechazar y prohibir materiales no reciclables, reducir la cantidad de residuos, disminuir los riesgos para la salud pública y el ambiente, desarrollar instrumentos de planificación, inspección y control, desarrollar una progresiva toma de conciencia por parte de la población, desarrollar políticas de responsabilidad extendida al productor, y promover el aprovechamiento de los residuos". (Solíz Torres, 2015, pág. 25).

Todo esto deriva en un desarrollo, necesario, de políticas enmarcadas en la protección de los ecosistemas y de la salud y bienestar de la sociedad. Estos mecanismos son denominados ecología política y que pudieran generar una serie de alternativas que garanticen la reutilización de estos desechos. Esta solución disminuiría el impacto ambiental, así como también produciría dividendos que ayuden a solventar los problemas de la sociedad.

Por lo tanto, esta investigación tiene como objetivo general analizar las políticas económicas que fomenten la transformación de basura orgánica e inorgánica en material de uso, como medidas del impacto ambiental. La metodología se basó en investigaciones de carácter documental y bibliográfico.

\section{Metodología.}

La generación de basura ha replanteado muchos aspectos que buscar rescatar la sostenibilidad y sustentabilidad de nuestro planeta y de la biodiversidad existente en ella. Para 


\section{Políticas económicas que fomenten la transformación de basura orgánica e inorgánica en material de uso, como medidas de impacto ambiental}

Vol. 3, núm. 3 Esp., (2019)

Miguel Ángel Núñez Núñez; Alfonso Gonzalo Torres Alvarado

ello se debe comprender y analizar la importancia del impacto ambiental, la contaminación de la basura orgánica e inorgánica, la transformación de la basura, las políticas internacionales de la transformación de la basura y las políticas económicas ecuatorianas para la transformación de la basura. Para esto se debe aplicar una metodología de carácter documental y bibliográfico a través de herramientas como textos, documentos y artículos científicos publicados disponibles en la web.

\section{Resultados.}

Transformación de la basura orgánica e inorgánica

Para poder comprender los fenómenos de transformación de la basura generada por el consumo excesivo de productos por parte de la sociedad, es necesario poder comprender el termino basura con el fin de poder determinar los pasos para dicha reutilización en otras áreas que no fue destinada en su procedo de manufactura o producción original. La basura es todo desecho orgánico e inorgánico, que debe ser eliminado por carecer de valor, donde la composición varía de acuerdo al desarrollo tecnológico y social siendo el desarrollo de la industria la responsable de los residuos generados actualmente(Venegas Guijarro, 2014).

Es decir, la basura se ha convertido en un problema de gran magnitud produciendo un impacto ambiental en los ecosistemas, pero sobre todo en la salud de los individuos por la germinación de moscas, insectos y roedores transmisores de múltiples enfermedades. Es necesario entonces poder determinar la clasificación de esta basura tal cual se detalla en la Tabla 1. 


\section{Políticas económicas que fomenten la transformación de basura orgánica e inorgánica en material de uso, como medidas de impacto ambiental}

Vol. 3, núm. 3 Esp., (2019)

Miguel Ángel Núñez Núñez; Alfonso Gonzalo Torres Alvarado

Tabla 1. Clasificación de los residuos sólidos

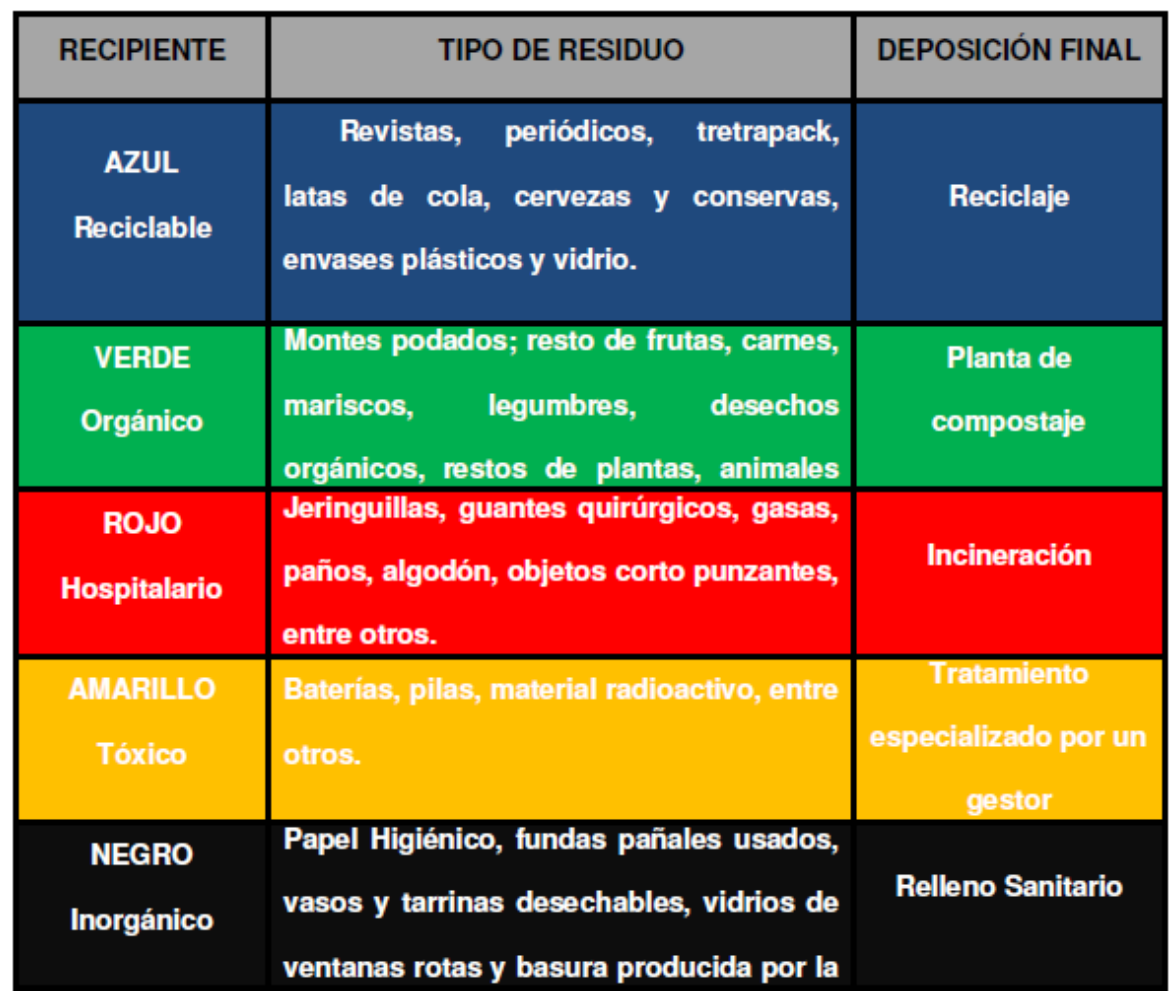

Fuente: (Venegas Guijarro, 2014)

Ecuador no escapa de la generación desmedida de la basura por lo que busca desarrollar el origen de este mal, surgido desde varios años y que se han convertido en la cultura de la población por lo que requiere de un cambio drástico de su forma de pensar y actuar ante el aumento exponencial de los deseos que ellos mismos han generado.

"La determinación socio histórica de la basura en Ecuador requiere, por ende, un análisis desde la geografía crítica, que parta de la comprensión de la estructura del territorio, de su lógica de apropiación y transformación de recursos, de las relaciones de poder, de los patrones de distribución y acceso, de la estructura poblacional, etc., y que las 


\section{Políticas económicas que fomenten la transformación de basura orgánica e inorgánica en material de uso, como medidas de impacto ambiental}

Vol. 3, núm. 3 Esp., (2019)

Miguel Ángel Núñez Núñez; Alfonso Gonzalo Torres Alvarado

relacione con la forma de generar, trasladar, disponer y tratar la basura en un espacio geográfica y temporalmente definido”. (García Batista, Machado López, \& Minuche, 2017, pág. 102).

Es por ello, que se deben platear una serie de soluciones que no solo permitan eliminar esta basura orgánica o inorgánica, sino que pueda transformarse en productos para el desarrollo socio económico del país. Dentro de estos planes se encuentra, por ejemplo, la lógica inversa. Son las actividades que involucran la administración, procesamiento, reducción y disposición de residuos o productos desde producción, residuos de embalaje (cajas, pallets, bidones, entre otros) y/o bienes usados por el cliente hasta el punto de origen, reproceso o destrucción (Gómez Montoya, 2011). En la Tabla 2 se puede visualizar dos grandes empresas que utilizan este tipo de proceso de logística inversa. 


\section{Políticas económicas que fomenten la transformación de basura orgánica e inorgánica en material de uso, como medidas de impacto ambiental}

Vol. 3, núm. 3 Esp., (2019)

Miguel Ángel Núñez Núñez; Alfonso Gonzalo Torres Alvarado

Tabla 2. Casos de aplicaciones a escala internacional de la logística inversa.

\begin{tabular}{l|l}
\hline \hline Casos de aplicaciones a escala internacional \\
\hline \hline \multirow{2}{*}{ Cisco $^{28}$} & $\begin{array}{l}\text { Cisco es una empresa multinacional dedicada a la fabricación, venta, mantenimiento y } \\
\text { consultoría de equipos de telecomunicaciones. }\end{array}$ \\
- Su logística inversa busca gestionar el retorno de los productos de sus clientes y distri- \\
buidores, con el fin de recuperarlos y redistribuirlos para recuperar su valor. \\
- Los procesos desarrollados son: logística de entrada, disposición, reciclaje, reúso, repara- \\
ción, gestión de inventarios y logistica de salida con los productos gestionados. \\
- Desarrolla procesos de logistica inversa consistentes, escalables, integrales, que permi- \\
tan gestionar la disposición o recuperación apropiada de los retornos, que conduzcan \\
a la reducción de costos, mejoren la satisfacción del cliente y promuevan la conciencia \\
ciudadana. \\
- Su logística inversa: a) recibe aproximadamente 30000 mil unidades por semana, b) \\
22.000.000 de lb de material son recicladas y c) representa I00.000.00 US por año. \\
- La logística inversa se considera como aspecto clave para la adecuada gestión y posicio- \\
namiento de la empresa, incluyendo la generación de valor.
\end{tabular}

Fuente: (Gómez Montoya, 2011)

Esta logística inversa tiene como principal protagonista al reciclaje. Consiste en seleccionar, separar, clasificar los residuos inutilizados para darle nuevas aplicaciones que contribuyan a la disminución de la contaminación ambiental, que en otros casos al no darle utilidad a los mismos son sometidos a técnicas que resultan el doble de contaminantes(González Ruiz, Zambrano, \& Estrella, 2017). En la Figura 4 se puede observar las etapas del reciclaje. 


\section{Políticas económicas que fomenten la transformación de basura orgánica e inorgánica en material de uso, como medidas de impacto ambiental}

Vol. 3, núm. 3 Esp., (2019)

Miguel Ángel Núñez Núñez; Alfonso Gonzalo Torres Alvarado

Figura 4. Etapas de reciclaje.

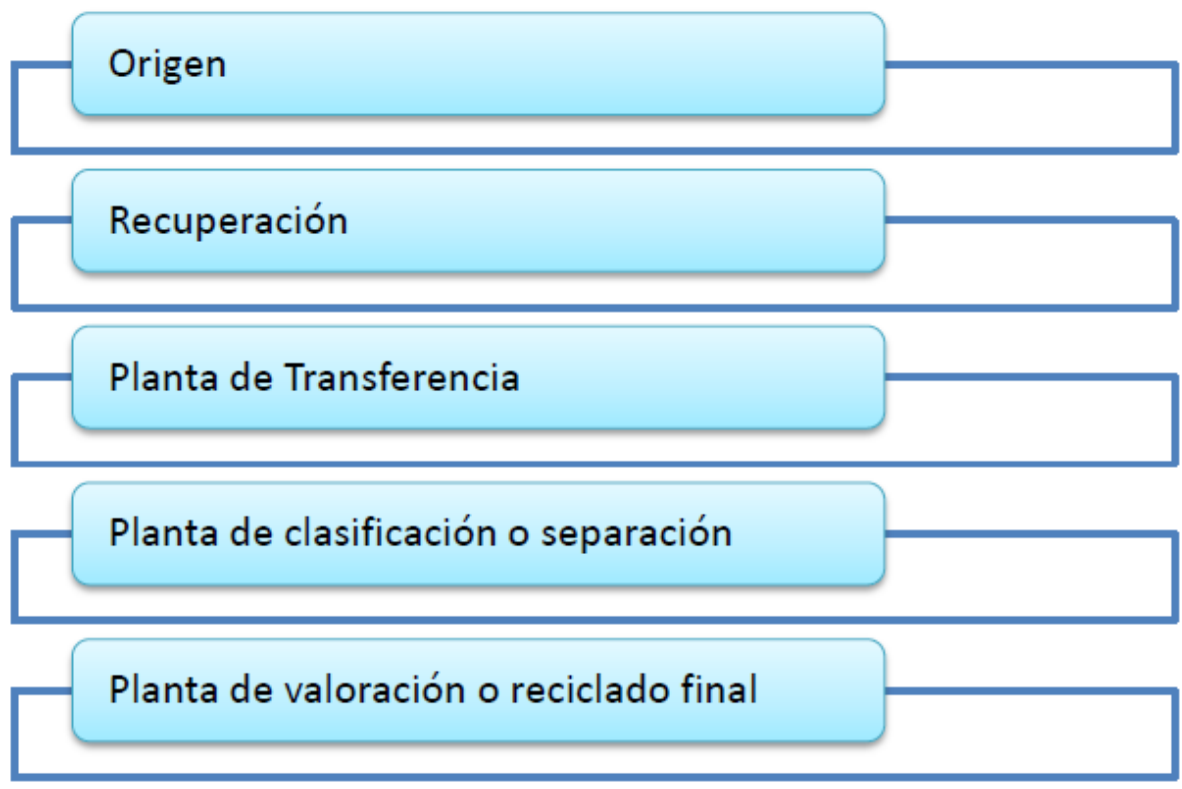

Fuente: (González Ruiz, Zambrano, \& Estrella, 2017)

Este proceso de reciclaje tiene efectos positivos en aquellas personas que lo ven como una actividad lucrativa. De esta manera algunas familias han convertido esta actividad en una alternativa de sustento, logrando una actividad organizada para atender a las necesidades de hogares de pequeños emprendedores (Castillo Criollo \& Ochoa Armijos, 2018). Aunado a esta importancia también prioriza el significado de la reutilización y el reciclaje como actividades que favorecen en la reducción de la generación de desechos y por ende en la disminución de impactos directos e indirectos al ambiente (reductores de calidad ambiental) (Palacios Jurado, 2017).

Es decir, estas actividades pueden generar nuevos productos que beneficien el ambiente, tales como fabricación de abonos o cajas de cartón provenientes de la basura orgánica y 


\section{Políticas económicas que fomenten la transformación de basura orgánica e inorgánica en material de uso, como medidas de impacto ambiental}

Vol. 3, núm. 3 Esp., (2019)

Miguel Ángel Núñez Núñez; Alfonso Gonzalo Torres Alvarado

procesado y empaquetado como materia prima en otros procesos de manufactura o producción provenientes de la basura inorgánica. En la Figura 5 se detalla un diagrama de bloque característicos de los usos posteriores de la basura y en la Figura 6 se muestra como son los diferentes tipos de cajas recicladas que se pueden producir con materia prima de basura.

Figura 5. Diagrama del proceso de transformación de basura orgánica e inorgánica.

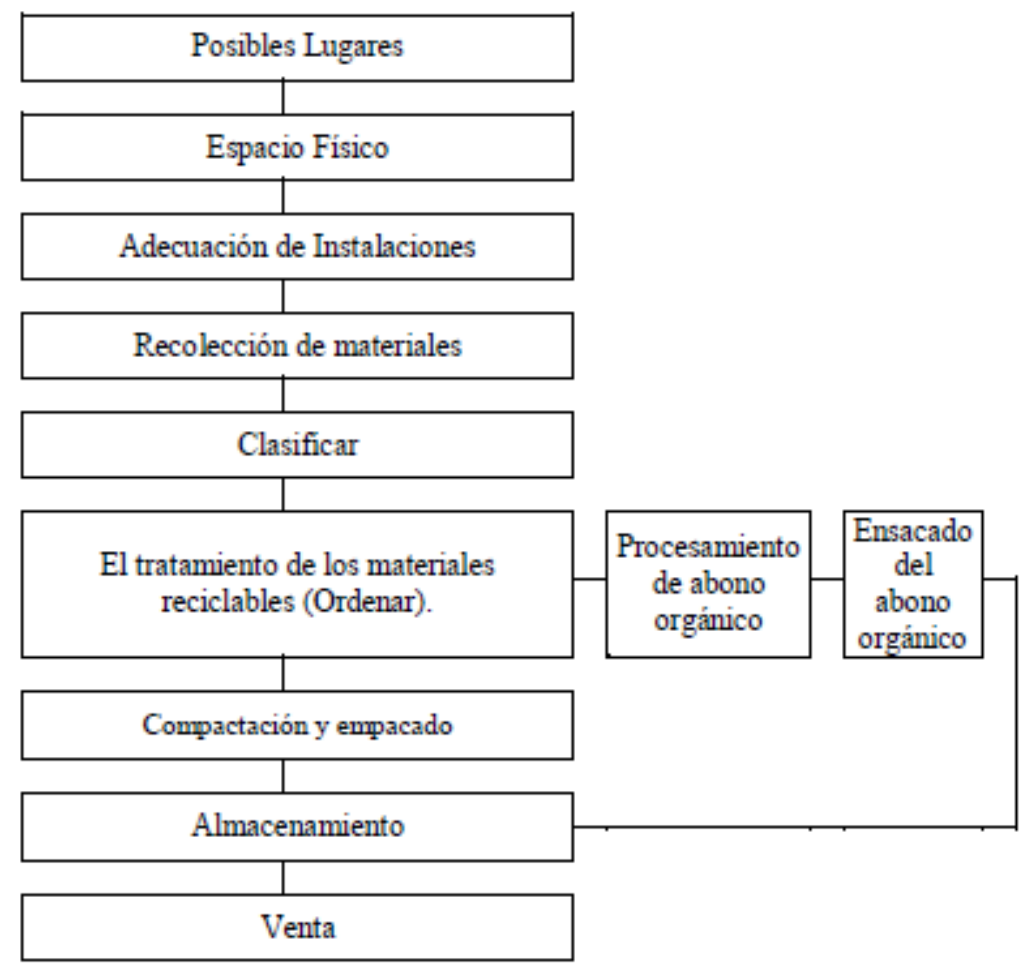

Fuente: (Andrade Campoverde \& Fernández S., 2014) 


\section{Políticas económicas que fomenten la transformación de basura orgánica e inorgánica en material de uso, como medidas de impacto ambiental}

Vol. 3, núm. 3 Esp., (2019)

Miguel Ángel Núñez Núñez; Alfonso Gonzalo Torres Alvarado

Figura 6. Tipos de cajas ecológicas para exportación.

\begin{tabular}{l|c|c|c|}
\hline & \multicolumn{2}{c}{ CAJAS DE CARTON } \\
\hline EMPAQUES & CARACTERISTICAS & USOS \\
Caja bananera & & $\begin{array}{l}\text { Son cajas 22xu y 280 para exportar } \\
\text { banano tanto a Europa, Estados Unidos y } \\
\text { Asia }\end{array}$
\end{tabular}
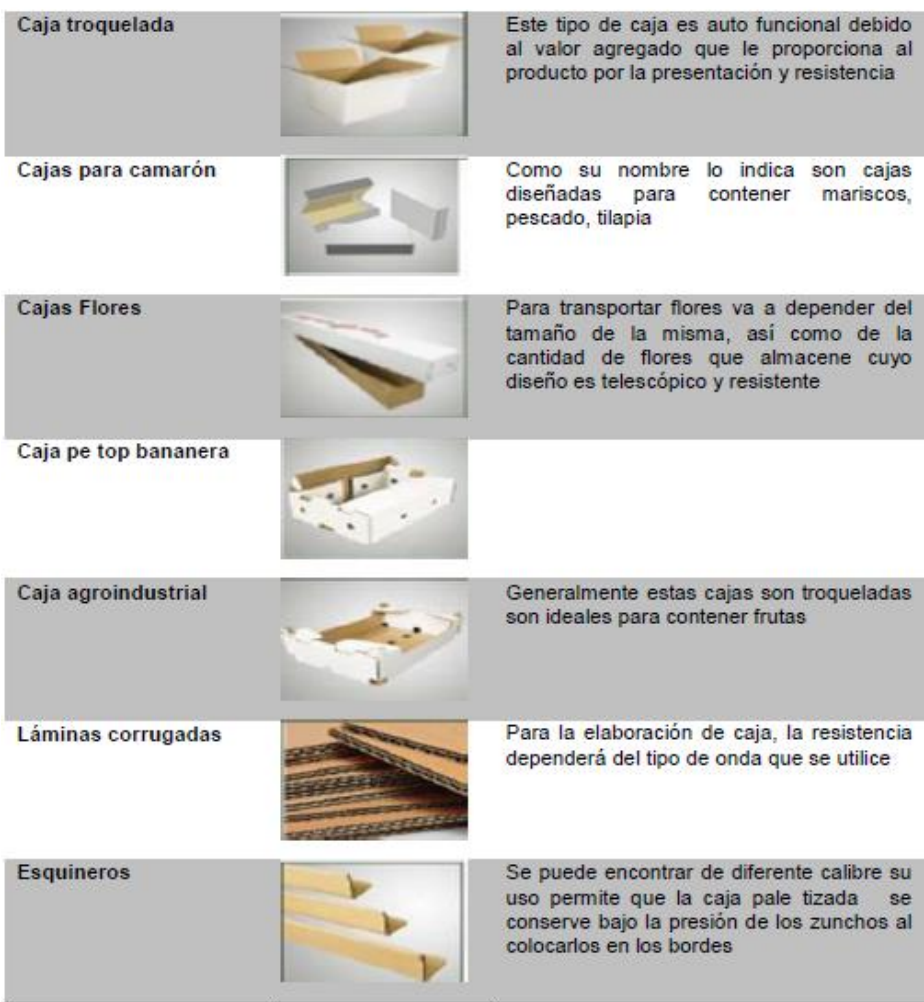

Fuente: (Castillo Criollo \& Ochoa Armijos, 2018)

La fabricación de abono orgánico es producto de la técnica del compostaje. Es un proceso de descomposición de la materia orgánica, la cual se lleva a cabo por numerosos microorganismos, bacterias, hongos e invertebrados como lombrices y cochinillas que viven en el suelo, a su vez estos organismos necesitan de un aporte de oxígeno constante(Suasnavas S., 2019). El proceso del compost se puede observar en la Figura 7. 


\section{Políticas económicas que fomenten la transformación de basura orgánica e inorgánica en material de uso, como medidas de impacto ambiental}

Vol. 3, núm. 3 Esp., (2019)

Miguel Ángel Núñez Núñez; Alfonso Gonzalo Torres Alvarado

Figura 7. Proceso para fabricación del compost (abono).

\section{El proceso del compostaje}

- Se colocará en la base del compostador una fina capa de material seco, que evite que los materiales se compacten y que permita la entrada de aire desde abajo.

- Encima de esta primera capa se echara una mezcla de materiales secos y verdes, en una proporción de una parte de seco por cada dos de verde. Esto presentará mejores condiciones de humedad, de textura y de nutrientes.

- Es importante que cada nueva aporte, el montón sea removido superficialmente, con un aireador o una horca.

- Cuando se evidencia que la parte inferior tiene un color oscuro y un olor agradable a tierra de bosque, ya se podrá retirar el compost.

- Los restos más leñosos tardan más tiempo en descomponerse, por lo que se podrá separarlos mediante el cribado del compost.

Fuente: (Suasnavas S., 2019)

Otro de los productos provenientes de la basura orgánica es la fabricación de biodiesel con la finalidad de poder generar energías renovables.

"El biogás es un biocombustible renovable compuesto por un $60 \%$ de metano y un $39 \%$ de dióxido de carbono; el restante 1\% concierne a cantidades trazas de ácido sulfhídrico, hidrógeno y nitrógeno. De manera artificial, este se genera por la descomposición de residuos orgánicos por medio de un proceso de fermentación anaeróbica en un depósito completamente cerrado y bajo temperaturas internas de $60^{\circ} \mathrm{C}$. Entre tanto, en la naturaleza se produce por la putrefacción (durante un periodo de tiempo mayor al artificial) de la materia orgánica, tomando el nombre de gas natural”. (Zúñiga, Recalde, \& Fuentes, 2015, pág. 7). 


\section{Políticas económicas que fomenten la transformación de basura orgánica e inorgánica en material de uso, como medidas de impacto ambiental}

Vol. 3, núm. 3 Esp., (2019)

Miguel Ángel Núñez Núñez; Alfonso Gonzalo Torres Alvarado

Este biogás puede ser utilizado en cualquier equipo comercial para uso de gas natural. El gas obtenido por fermentación tiene un octanaje que oscila entre 100 y 110, lo cual lo hace muy adecuado para su uso en motores de alta relación volumétrica de compresión, por otro lado, una desventaja es su baja velocidad de encendido (Silva, 2007). En la Figura 8 se visualiza el uso o aplicaciones que tiene el biogás.

Figura 8. Aplicaciones que tiene el biogás.

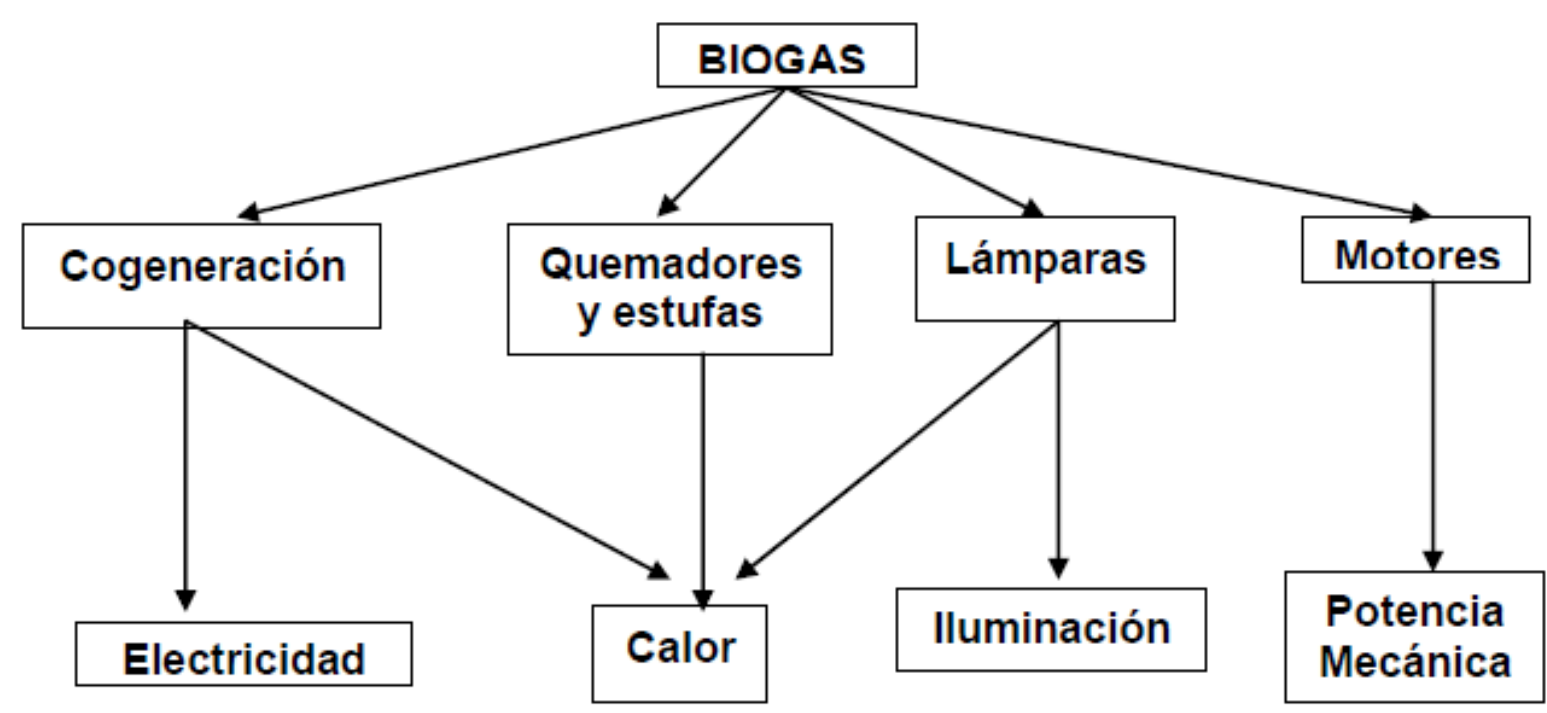

Fuente: (Silva, 2007)

Políticas y mecanismos que favorecen la transformación de la basura

La transformación de la basura en producto que sean beneficiosos a la colectividad, pero sobre todo al medio ambiente es fundamental y casi debe convertirse en u fenómeno cultural y en un nuevo paradigma de la sociedad. Se debe transformar la cultura de los individuos en busca de obtener un mejor mundo sostenible y sustentable a las nuevas generaciones. La transformación 


\section{Políticas económicas que fomenten la transformación de basura orgánica e inorgánica en material de uso, como medidas de impacto ambiental}

Vol. 3, núm. 3 Esp., (2019)

Miguel Ángel Núñez Núñez; Alfonso Gonzalo Torres Alvarado

de estas basuras deben ser materia de interés en todas las aristas económicas y políticas de los países.

Ya se ha tomado en consideración en numerosas convenciones mundiales debido a la crisis del cambio climático y de los gases invernadero. Es grave la contaminación y por ende se debe actuar en búsqueda de volver al equilibrio ecológico. Existen mecanismos que pueden apoyar esta transformación. El reciclaje es una actividad de estos mecanismos. Uno de ellos es la economía circular. En la Figura 9 se detalla el significado de la economía circular que se debe utilizar no solo en el sector productivo e industrial sino desde los hogares y las personas.

Figura 9. Representación integral de la lógica económica y empresarial incrustada en el concepto de economía circular.

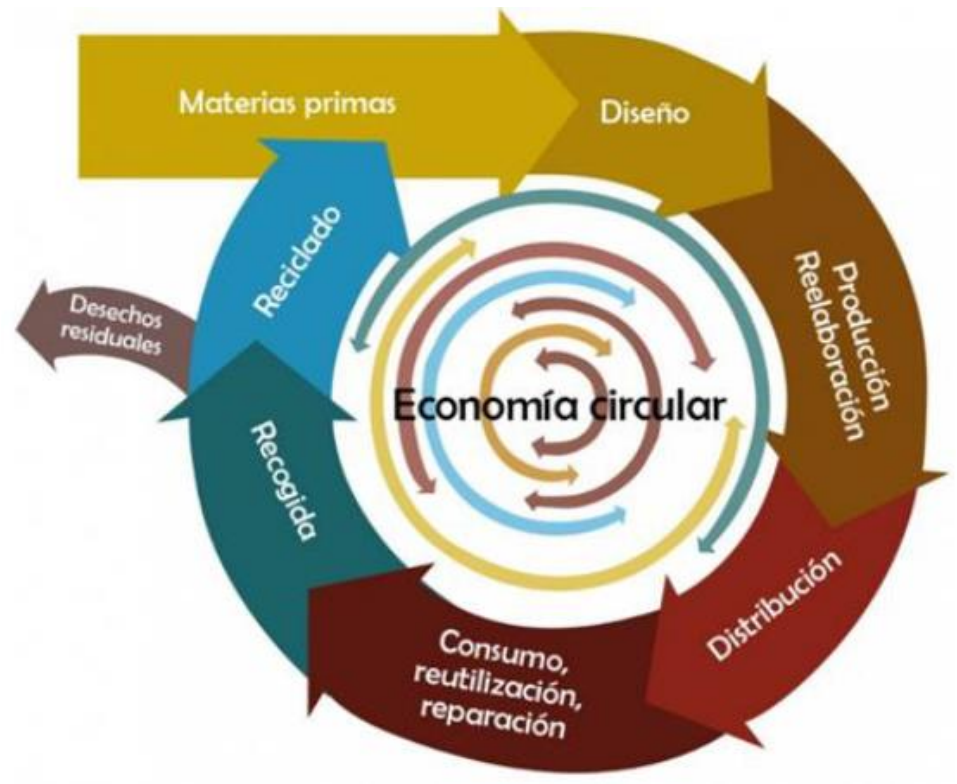

Fuente: (Morocho, Donoso, \& Valenzuela, 2018) 


\section{Políticas económicas que fomenten la transformación de basura orgánica e inorgánica en material de uso, como medidas de impacto ambiental}

Vol. 3, núm. 3 Esp., (2019)

Miguel Ángel Núñez Núñez; Alfonso Gonzalo Torres Alvarado

“Una economía circular es un sistema industrial que es restaurativo o regenerativo por intención y diseño. Sustituye al concepto de fin de vida con restauración, cambios hacia el uso de energías renovables, elimina el uso de productos con químicos tóxicos, que perjudican la reutilización y reintegración a la biosfera, y tiene como objetivo la eliminación de desechos a través del diseño superior de materiales, productos, sistemas y modelos de negocios”. (Morocho, Donoso, \& Valenzuela, 2018, pág. 143).

Por supuesto, para lograr que estos mecanismos se apliquen deben acontecer una serie de circunstancias significativas que precipite el interés de los que pueden ejercer la política en el país. El catalizador para ello es la evaluación del impacto ambiental. Uno de los agentes que puede llegar a determinar altos índices de impacto ambiental es la basura, pero fundamentalmente la forma y fondo de las técnicas de eliminación que puedan hacer los estados. En la Figura 10 se ilustra la relación, a nivel cantonal, entre densidad poblacional, tipos de disposición final y producción de residuos per cápita en la república de Ecuador (Solíz Torres, 2015). 


\section{Políticas económicas que fomenten la transformación de basura orgánica e inorgánica en material de uso, como medidas de impacto ambiental}

Vol. 3, núm. 3 Esp., (2019)

Miguel Ángel Núñez Núñez; Alfonso Gonzalo Torres Alvarado

Figura 10. Basura per cápita, condiciones de disposición final y densidad poblacional en el

Ecuador.

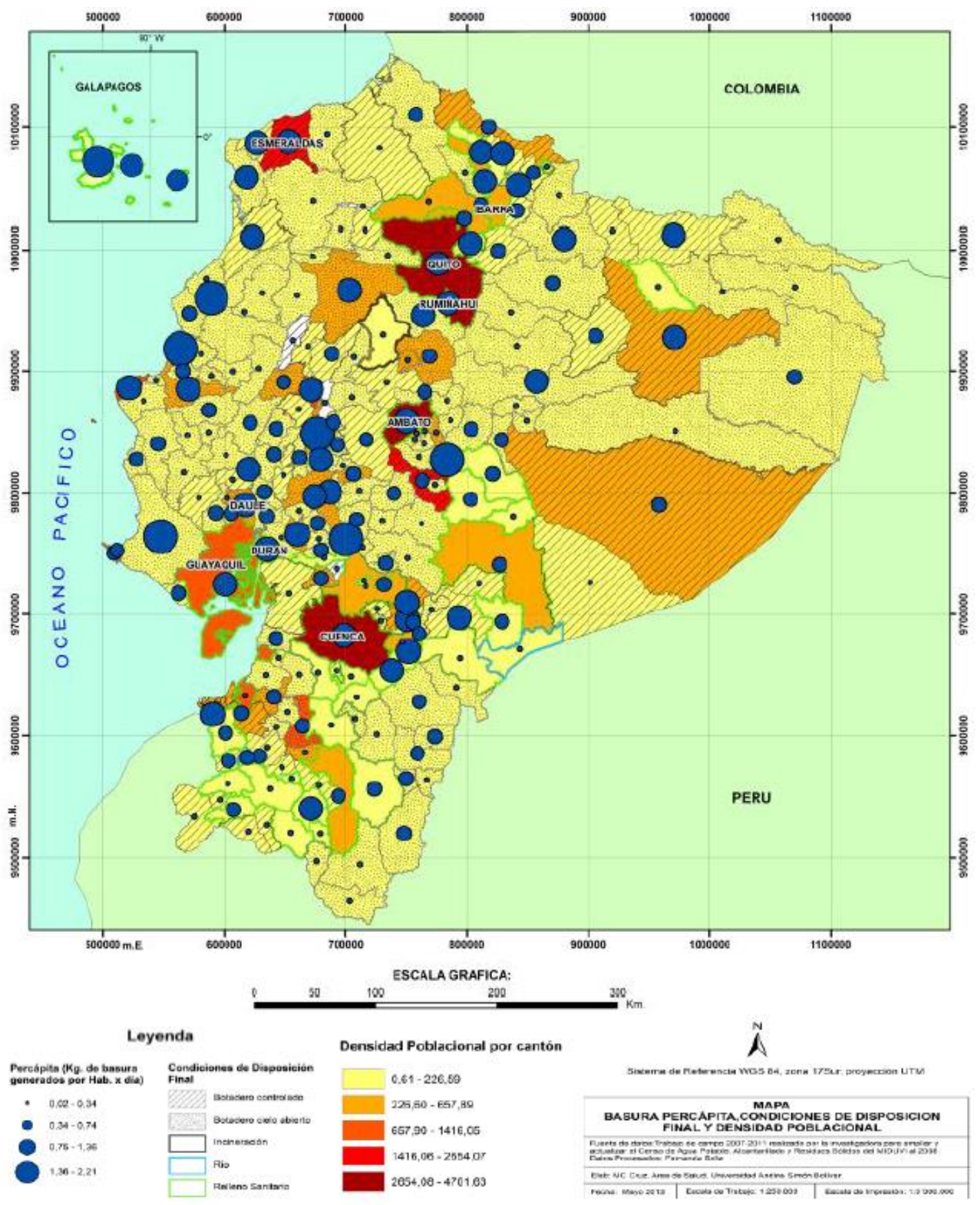

Fuente: (Solíz Torres, 2015) 


\section{Políticas económicas que fomenten la transformación de basura orgánica e inorgánica en material de uso, como medidas de impacto ambiental}

Vol. 3, núm. 3 Esp., (2019)

Miguel Ángel Núñez Núñez; Alfonso Gonzalo Torres Alvarado

Lamentablemente, las políticas en torno al cuidado del medio ambiente no hacen mella en la siquis de las organizaciones y de los ciudadanos. Deben buscar diferentes formas de poder trasladar el verdadero problema de la contaminación del suelo, aire y agua que genera la basura. La crisis del desecho evidencia la insustentabilidad e insostenibilidad de este modelo de desarrollo, y devela la urgencia de realizar políticas que apuesten por el fortalecimiento de los procesos organizativos, la recampesinización, la producción, procesamiento y comercialización a escalas local y comunitaria (Solíz Torres, 2015). Por ejemplo, lo que sucede en Esmeraldas y su rampante deforestación y explotación minera en los ríos o la desertificación y erosión de la Costa y Sierra, causado por el desarrollo de los países mucho más grandes y poderosos que el económico en el Ecuador(Meza Bajaña, 2013).

En el 2007, en Ecuador se realiza un Censo Nacional de Agua Potable, Alcantarillado y Residuos Sólidos. En ella se pone en evidencia la falta de acceso, la privatización de competencias y los importantes déficits presupuestarios que origina, en los gobiernos locales, la prestación de los servicios de aseo urbano (Solíz Torres, 2015).

Es necesario que el estado apunte a nuevas políticas que no solo ejecuten penalizaciones administrativas y judiciales sino también genere concientización en el colectivo a través de propaganda en los medios de comunicación, apoyados en las TIC. Es por ello, que los estados deben apostar por modelos soberanos, reparadores del metabolismo social, la basura retorna a su estructura cíclica en tanto fertilizante de la tierra y provisor de materia prima renovable (Solíz Torres, 2015). 


\section{Políticas económicas que fomenten la transformación de basura orgánica e inorgánica en material de uso, como medidas de impacto ambiental}

Vol. 3, núm. 3 Esp., (2019)

Miguel Ángel Núñez Núñez; Alfonso Gonzalo Torres Alvarado

Aunque, en la constitución dela república del Ecuador se ha tomado en cuenta la conservación del media ambiente y d ellos ecosistemas, se necesitan más leyes y normas que puedan apoyar tales objetivos. En la constitución expresa lo siguiente:

"El marco básico incluye una sección sobre "derechos de la naturaleza", junto a otra referida a los derechos del "buen vivir" (incluidas normas sobre el "ambiente sano"). Este marco se complementa con una descripción del régimen de desarrollo (título VI) y una elaboración más detallada sobre el régimen del buen vivir (título VII)”. (Gudynas, 2009, pág. 36).

El mecanismo que puede apoyar una fuerte generación de leyes y normativas son las evaluaciones del impacto ambiental, la cual puede ser la herramienta para la prevención.

"En el Ecuador, se encuentra contenida en la Ley de Gestión Ambiental como un requerimiento previo y obligatorio en orden a obtener la licencia ambiental que autoriza la ejecución de un proyecto determinado. Tanto en la LGA como en el TULAS VI, la evaluación del impacto ambiental se circunscribe a la regulación de la calidad ambiental para preservar las condiciones de la calidad de vida humana existentes que implican también la preservación de las condiciones ambientales”.(Correa B., 2015, pág. 192).

Aspectos económicos que favorecen la transformación de la basura

En el Ecuador existen mecanismos que valoran el respeto al medio ambiente y a su biodiversidad por lo que es garante de buscar las formas para poder contrarrestar lo negativo de los desperdicios o basura generada por la sociedad. Sin duda alguna, la recesión económica de 


\section{Políticas económicas que fomenten la transformación de basura orgánica e inorgánica en material de uso, como medidas de impacto ambiental}

Vol. 3, núm. 3 Esp., (2019)

Miguel Ángel Núñez Núñez; Alfonso Gonzalo Torres Alvarado

hace unos años no permitió la generación de basura pero que al momento del fortalecimiento de la economía esta se multiplico a cantidades grandes debido a que los individuos poseían mayores recursos económicos y por lo cual podían consumir más productos.

“En los períodos de gran inflación en los años 1988 - 1989, la cantidad de residuos disminuyó considerablemente. Por el contrario, desde la aplicación del Plan de Convertibilidad en 1991, que progresivamente fue estabilizando la economía, el tonelaje de residuos recibido ha aumentado progresivamente hasta llegar al récord de 4 millones de toneladas en 1993”.(Batallas Tinoco, 2001, pág. 54).

Esto quiere decir que indudablemente la generación de basura es directamente proporcional a economía de la nación. Queda poder instaurar en la sociedad una cultura en pro de transformar la basura en material de uso. Es decir, cambiar de paradigma. Se pasa de la idea de bote los desperdicios por la ventana, hacia la idea de que la basura tiene valor si es bien gestionada, y si no lo es, genera conflictos socio ambientales de importancia (Cuvi, 2015).

Esto permite que se generen nuevos conocimientos en pro de la búsqueda de soluciones a este flagelo de la basura. Uno de estos nuevos términos es la bioeconomía. Es una opción sinérgica entre los ámbitos biológico y socioeconómico promoviendo un sistema productivo sostenible coevolucionado, donde su fundamento está en la construcción de conocimiento a partir de los recursos naturales de un territorio, lo que hoy denominamos bioconocimiento (Lugo-Morin, 2018).

"La bioeconomía se distingue de la Economía Ecológica porque la primera se fundamenta en el bioconocimiento, es decir, el ámbito biológico y el ámbito 


\section{Políticas económicas que fomenten la transformación de basura orgánica e inorgánica en material de uso, como medidas de impacto ambiental}

Vol. 3, núm. 3 Esp., (2019)

Miguel Ángel Núñez Núñez; Alfonso Gonzalo Torres Alvarado

socioeconómico actúan en sinergia para promover un sistema productivo sostenible coevolucionado. Mientras que la Economía Ecológica estudia las posibilidades del modelo económico en un contexto de sostenibilidad, es decir, la biosfera es reconocida como elemento fundamental de la vida, por lo tanto, la economía debe desarrollarse dentro de los limites ecológicos del planeta”. (Lugo-Morin, 2018, pág. 76)

La bioeconomía debe estar en la palestra de las políticas de los garantes del funcionamiento del estado. Debe estar en las normativas y leyes de aquellos mecanismos que involucren, no solo, a los procesos que dañen al medio ambiente, sino también aquellos que involucren un daño a la salud y seguridad del trabajador o de los individuos que estén involucrados en dicho proceso.

Es necesario obtener unos beneficios económicos para poder, primero eliminar la cantidad máxima posible de basura que contamine el ecosistema y segundo poder generar financiamiento propio de estas mismas sociedades con la reutilización de estos desechos. Uno de los productos que están tomando la batuta en la generación de dividendos es la producción de biogás por medio de la basura o desechos como materia prima. Para ello es necesario poder observar los beneficios económicos:

“a) Producción del gas metano, el mismo que se puede utilizar para la calefacción y la iluminación, reduciendo así el uso de energía eléctrica del área donde se desarrolla el proceso de producción de biogás. Esta es una manera de producir energía que no es contaminante en su proceso ni en su combustión, contrario a lo que sucede con los combustibles fósiles, b) producción de bio abono de alta calidad, c) Reducción de costos 


\section{Políticas económicas que fomenten la transformación de basura orgánica e inorgánica en material de uso, como medidas de impacto ambiental}

Vol. 3, núm. 3 Esp., (2019)

Miguel Ángel Núñez Núñez; Alfonso Gonzalo Torres Alvarado

por desplazamiento de energía eléctrica fósil por energías renovables y d) beneficios macro económicos a través de la generación descentralizada de energía”. (Zúñiga, Recalde, \& Fuentes, 2015, pág. 9)

Si se extrapola estos beneficios a otros productos que deriven del uso de la basura en pro de un beneficio económico y a su vez ayuden a mejorar las condiciones ambientales entonces se está logrando el objetivo. Para que se logre estos planteamientos deben existir políticas de financiamiento que fortalezcan estos biomecanismos. Por lo cual, estas políticas de financiamiento deben tomar en consideración ciertos factores que están relacionados, tal como se detalla en la Tabla 3.

Tabla 3. Políticas de financiamiento en la gestión de residuos.

FACTORES

Prioridades

Territoriales

\section{CARACTERÍSTICAS}

Están pueden ser nacionales, regionales o locales, y dependen fuertemente de la agenda política de los gobiernos.
Prioridades

Sectoriales
De existir una autentica gestión ambiental regional, esta debe armonizarse con el ordenamiento territorial y contribuir a este, de manera de lograr que las regiones impulsen programas de desarrollo compatibles con las capacidades de sus recursos. 


\section{Políticas económicas que fomenten la transformación de basura orgánica e inorgánica en material de uso, como medidas de impacto ambiental}

Vol. 3, núm. 3 Esp., (2019)

Miguel Ángel Núñez Núñez; Alfonso Gonzalo Torres Alvarado

No hay que olvidar que en la mayoría de nuestros países la gestión ambiental se da fundamentalmente en los sectores donde se mantiene una importante cuota de poder en términos de atribuciones, muchas de ellas sancionadas por ley. Los servicios de agua, salud, transporte, agricultura, patrimonio nacional, etc., tienen generalmente más injerencia en la gestión del medio ambiente y los recursos naturales que la propia autoridad ambiental, normalmente débil.

Existe en los países un enorme retraso en gestión de los residuos que se suele llamar "pasivo ambiental", que ha conducido en Déficits acumulados diversos casos, particularmente en las grandes ciudades, al colapso de los sistemas de recolección y disposición de tales recursos.

Experiencias y lecciones
Existen a nivel mundial diversos ejemplos relevantes de formas de financiamiento de proyectos de residuos. Por ejemplo, en Alemania se mencionan relaciones beneficio/costo entre $1 / 1 \mathrm{y}$ 1/5 para iniciativas tales como la reducción de emisiones de $\mathrm{SO}_{2}$ provenientes del combustible Diesel, introducción de convertidores catalíticos, reducción de nitratos en el agua potable debido a medidas tomadas respecto a la actividad agrícola, reducción del ruido en el transporte carretero y preservación de la diversidad biológica.

Existen diferentes percepciones tanto de parte de los

Percepciones agentes/actores acerca de la calidad ambiental, como de sus posibilidades de aceptar cambios favorables y/o desfavorables. El ámbito de las percepciones ha sido relativamente 


\section{Políticas económicas que fomenten la transformación de basura orgánica e inorgánica en material de uso, como medidas de impacto ambiental}

Vol. 3, núm. 3 Esp., (2019)

Miguel Ángel Núñez Núñez; Alfonso Gonzalo Torres Alvarado

menospreciado en la política ambiental latinoamericana, en el fondo negado, o al menos mediatizando la competencia de la población para opinar sobre la degradación ambiental.

Dificultades de

Se debe tratar como un problema de armonía y concertación

financiamiento una parte importante de la gestión ambiental es todavía financiada por la cooperación internacional.

Fuente: (Leal, 1996)

\section{Conclusiones.}

Una de las consecuencias más importante que se genera por la constante producción de basura es el impacto ambiental a los diversos ecosistemas produciendo un daño, en algunas ocasiones irreversibles, a la biodiversidad o a la salud de los individuos que habitan en ese sector contaminado. La evolución de la sociedad ha traído consigo un crecimiento en diferentes aristas, una de ellas en el aspecto económico. Este ha permitido poder garantizar no solo las necesidades básicas sino también poder establecer un consumo más amplio de producto ya no tan necesarios. Esto es lo que llaman los expertos, la obsolescencia programada, es decir la necesidad de comprar, comprar y comprar sin necesidad. Esto produce, por supuesto, una alta generación de basura que impacta al medio ambiente.

Este impacto ya está siendo tomado en cuenta y requiere de una evaluación para conocer y determinar qué tan problemático va a ser transformar un producto o un sistema en un determinado sector territorial. Por supuesto bajo los parámetros de la calidad de la biodiversidad 


\section{Políticas económicas que fomenten la transformación de basura orgánica e inorgánica en material de uso, como medidas de impacto ambiental}

Vol. 3, núm. 3 Esp., (2019)

Miguel Ángel Núñez Núñez; Alfonso Gonzalo Torres Alvarado

y de la seguridad y ambiente a la cual estarán sometidos los individuos. La evaluación del impacto ambiental está garantizando que tan peligroso puede ser el cambio de la morfología de un sitio y que tanto puede alterar la sostenibilidad de los ecosistemas.

La contaminación en base a la generación de basura orgánica e inorgánica ha conllevado a replantear diversas situaciones a través de la aplicación de nuevas normas y leyes que permitan poder defender lo que en si no puede defenderse por sí sola. La creación de normas internacionales de protección al medio ambiente son garantes para la protección de la biodiversidad. Lamentablemente la aplicación de dichas normativas no es ejecutada por las grandes corporaciones las cuales siguen en su afán de poder producir a cuestas de la salud laboral o del daño a los ecosistemas.

Es allí donde entra un nuevo término para solventar la generación de basura que cada vez se torna exponencial y es el desarrollo de producto proveniente de la materia prima como la basura. Estos productos son trabajados con la finalidad de que puedan brindar un beneficio en el aumento de la calidad de vida de la sociedad a través de diversos mecanismos como la fabricación de abono y biodiesel, reciclado de material plástico para la reutilización y fabricación de material, la conversión de la chatarra metálica en nuevas estructuras de construcción, la transformación de cauchos en nuevos productos de jardinería, entre muchos otros. Es decir, es factible la reutilización de estos desechos en nuevos productos que permitirán seguir manteniendo la calidad de vida de los individuos.

Por supuesto, esto debe generar tanto nuevas perspectivas y nuevos conocimientos que permitan el desarrollo de estas nuevas tecnologías renovables. Un nuevo término es la economía 


\section{Políticas económicas que fomenten la transformación de basura orgánica e inorgánica en material de uso, como medidas de impacto ambiental}

Vol. 3, núm. 3 Esp., (2019)

Miguel Ángel Núñez Núñez; Alfonso Gonzalo Torres Alvarado

circular donde el factor más importante es el reciclaje. Con esto permite darle garantía en la utilización de la basura orgánica e inorgánica como materia prima en el sistema productivo de las empresas. Estos reciclajes tienen nuevos fundamentos y nuevas perspectivas que permiten el desarrollo de bioconocimientos que buscan dar garantía a lo anteriormente planteado.

Para que se pueda producir todos estos efectos positivos en pro del medio ambiente y de la salud y bienestar de la sociedad se deben cumplir ciertas políticas que permitan fortalecer desde el punto de vista administrativo o jurídico el desarrollo de estas nuevas tecnologías. Son los gobiernos a través de sus mecanismos las cuales deben brindar el apoyo en la formación de nuevos conocimientos, pero también en el cambio de paradigma de la sociedad aplicando hacia una nueva cultura de preservación y conservación fomentada en la reutilización delos productos que han perdido su vida útil. Por lo tanto, estas políticas deben ir enmarcada en nuevos procesos económicos aplicando formas de financiamiento, tanto a los proyectos como a la generación de dividendos, que permitan poder establecer una mejor calidad de vida y una protección al medio ambiente.

\section{Bibliografía.}

Andrade Campoverde, G. M., \& Fernández S., D. J. (2014). Proyecto de factibilidad para la creación de una micro-empresa, para la clasificación de desechos orgánicos e inorgánicos en el Cantón Cañar. Cuenca: Trabajo de Grado - UNIVERSIDAD POLITÉCNICA SALESIANA.

Batallas Tinoco, E. V. (2001). Recolección y tratamiento de la basura en la ciudad de Quito, posibles soluciones para preservar el medio ambiente, salubridad, y como fuente generadora de recursos económicos. Quito, Ecuador: Trabajo de Grado - INSTITUTO DE ALTOS ESTUDIOS NACIONALES, XXVIII CURSO SUPERIOR DE SEGURIDAD NACIONAL Y DESARROLLO. 


\section{Políticas económicas que fomenten la transformación de basura orgánica e inorgánica en material de uso, como medidas de impacto ambiental}

Vol. 3, núm. 3 Esp., (2019)

Miguel Ángel Núñez Núñez; Alfonso Gonzalo Torres Alvarado

Castillo Criollo, F., \& Ochoa Armijos, K. E. (2018). La importancia de utilizar empaques y embalajes amigables con el medio ambiente para exportaciones desde Ecuador. Observatorio de la Economía Latinoamericana, 1-12.

Coria, I. D. (2008). El estudio de impacto ambiental: características y metodologías. Invenio, $11(20), 125-135$.

Correa B., E. W. (2015). El esquema normativo ecuatoriano aplicable a la evaluación de impacto ambiental; materializa el principio de prevención? enfoque en areas naturales protegidas. Quito, Ecuador: Trabajo de Grado - Universidad San Francisco de Quito, Colegio de Jurisprudencia.

Cuvi, N. (2015). Residuos sólidos en América Latina: gestión, políticas públicas y conflictos socioambientales. En J. Ponce, Residuos sólidos en America Latina (págs. 1-3). Quito, Ecuador: Letras Verdes. Revista Latinoamericana de Estudios Socioambientales.

Espinoza, G. (2001). Fundamentos de evaluación de impacto ambiental. Santiago de Chile: Banco Interamericano De Desarrollo-Bid. Centro De Estudios Para El Desarrollo-Ced.

García Batista, R. M., Machado López, L., \& Minuche, J. L. (2017). Plan de gestión ambiental de desechos sólidos en la Empresa productora de banano, Herederos Coronel, del Cantón Machala, Ecuador. Revista Universidad y Sociedad, 9(1), 100-105.

Gómez Montoya, R. A. (2011). Logística inversa un proceso de impacto ambiental y productividad. Producción más Limpia, 5(2), 63-79.

González Ruiz, M. D., Zambrano, M., \& Estrella, N. (2017). Aprovechamiento y clasificación de Residuos Plásticos para la elaboración de materia prima Base. Guayaquil, Ecuador: Trabajo de Grado - Universidad de Guayaquil, Facultad de Ingeniería Química.

Gudynas, E. (2009). La ecología política del giro biocéntrico en la nueva Constitución de Ecuador. Revista de estudios sociales(32), 34-47.

Leal, J. (1996). Aspectos económicos de la gestión de residuos. CEPAL.

Lugo-Morin, D. R. (2018). Bioeconomía: una revisión desde la experiencia de Ecuador y Bolivia. Coyuntural, Revista de temas de coyuntura y perspectivas, 3(3), 73-92.

Macías Fuentes, A. F. (2011). Estudio de impacto ambiental del nuevo relleno sanitario del cantón Paján, provincia de Manabí, Ecuador. Pinar del Río, Ecuador: Trabajo de Grado Universidad de Pinar del Río.

Meza Bajaña, A. J. (2013). Políticas nacionales e internacionales tendientes a la conservación del medio ambiente en el Ecuador: un análisis del calentamiento globlal y su efecto en nuestro país. Guayaquil, Ecuador: Trabajo de Grado - Universidad de Guayaquil, 


\section{Políticas económicas que fomenten la transformación de basura orgánica e inorgánica en material de uso, como medidas de impacto ambiental}

Vol. 3, núm. 3 Esp., (2019)

Miguel Ángel Núñez Núñez; Alfonso Gonzalo Torres Alvarado

Instituto Superior de Post-Grado en Ciencias Internacionales" Dr. Antonio Parra Velasco".

Morocho, F. R., Donoso, D. N., \& Valenzuela, M. A. (2018). Economía circular: un camino hacia un Quito más sostenible. INNOVA Research Journal, 3(11), 139-158.

Orellana Salas, J. A., Portilla, L., \& Del Cisne, T. (2018). Uso e importancia de los recursos naturales y su incidencia en el desarrollo turístico. Caso Cantón Chilla, El Oro, Ecuador. Revista interamericana de ambiente y turismo, 14(1), 65-79.

Palacios Jurado, M. J. (2017). Valoracion de los resuduos generados de una planta indistrial de plásticos Tans SA de la ciudad de Durán y su rehúso como sustituto de materias primas. Samborondón: Trabajo de Grado - Universidad de especialidades Espíritu Santo.

Perevochtchikova, M. (2013). La evaluación del impacto ambiental y la importancia de los indicadores ambientales. Gestión y política pública, 22(2), 283-312.

Sánchez, L. E. (2011). Evaluación de impacto ambiental. Conceptos y métodos. Bogotá: ECOE Ediciones.

Silva, O. (2007). Rediseño del prototipo para generar electricidad usando materia orgánica (basura). Sangolqui: Trabajo de Grado - Escuela Politécnica del Ejército.

Solíz Torres, M. F. (2015). Ecología política y geografía crítica de la basura en el Ecuador. Letras Verdes. Revista Latinoamericana de Estudios Socioambientales(17), 4-28.

Suasnavas S., A. G. (2019). Manual para el tratamiento de desechos orgánicos, inorgánicos y no aprovechables en la carrera de Gastronomía de la Universidad de Los Hemisferios. Quito: Trabajo de Grado - Universidad de Los Hemifesrios.

Torres, C. (2010). Estudio de impacto ambiental ex-post para la industria textil del Canton Pelileo-provincia de Tungurahua-Ecuador. Obtenido de Conoma: http://www.conama11. vsf. es/conama10/download/files/conama11/CT, 202010, 186699893.

Venegas Guijarro, R. X. (2014). Sistema de Tratamiento de Basura Orgánica e Inorgánica para la Fragata" Presidente Eloy Alfaro" de la Armada del Ecuador y su contribución a disminuir la contaminación marina que produce durante los periodos de navegación. Salinas, Ecuador: Trabajo de Grado - Universidad de las Fuerzas Armadas ESPE. ESSUNA. Carrera de Licenciatura en Ciencias Navales.

Wathern, P. (1988). An introductory guide to EIA. In: P. Wathern (org.), Environmental impact assessment. Theory and practice. Unwin Hyman, London, 1(1), 3-30.

Zúñiga, M. E., Recalde, M. F., \& Fuentes, J. A. (2015). La producción de biogás por degradación de abono orgánico como alternativa de energía en Ecuador. Revista DELOS Desarrollo Local Sostenible, 1-14. 
Políticas económicas que fomenten la transformación de basura orgánica e inorgánica en material de uso, como medidas de impacto ambiental

Vol. 3, núm. 3 Esp., (2019)

Miguel Ángel Núñez Núñez; Alfonso Gonzalo Torres Alvarado

$$
\text { (9) }(1)(0)
$$

\section{RECONOCIMIENTO-NOCOMERCIAL-COMPARTIRIGUAL}

CC BY-NC-SA

ESTA LICENCIA PERMITE A OTROS ENTREMEZCLAR, AJUSTAR Y CONSTRUIR A PARTIR DE SU OBRA CON FINES NO

COMERCIALES, SIEMPRE Y CUANDO LE RECONOZCAN LA AUTORÍA Y SUS NUEVAS CREACIONES ESTÉN BAJO UNA LICENCIA CON LOS MISMOS TÉRMINOS. 